\title{
Reflections on the Case of Bamiyan
}

\author{
Jukka Ilmari Jokilehto
}

\begin{abstract}
Inscribed in the World Heritage List in 2003, the Bamiyan cultural landscape has been subject to conservation management efforts, including the proposal to reconstruct at least one of the Buddha figures after the 2001 destruction. This paper examines some of the fundamental concepts of conservation and restoration of cultural heritage referred to in international recommendations. These include the question of reconstruction in reference to the notions of integrity and authenticity as they would apply in the case of Bamiyan cultural landscape and its archaeological remains. In fact, the conservation of cultural heritage is fundamentally a cultural problem. In the case of Bamiyan, the present-day culture has changed from the historical Buddhist era, when the Buddha figures had a distinct role in society. Any reconstruction of the figures originally carved from the rock would thus be 'inauthentic'. Instead, it is necessary to focus on the presentation and interpretation of the splendid historical features, recognised for their outstanding universal value within the wider cultural and natural landscape, also considering the needs and requirements of the present-day society.
\end{abstract}

Keywords Bamiyan Buddhas · Conservation · Restoration · Reconstruction · Integrity $\cdot$ Authenticity $\cdot$ Anastylosis $\cdot$ Cultural landscape $\cdot$ World Heritage

\section{World Heritage Inscription of Bamiyan}

At its seventh session in 1983, the Bureau of the World Heritage Committee (UNESCO 1983) recommended the inscription of 35 properties. As part of this group, the Monuments of the Bamiyan Valley was recommended for inscription on the basis of criteria (ii) (iv), 'on the condition that the authorities define a large

Published jointly by the United Nations Educational, Scientific and Cultural Organization (UNESCO), 7, place de Fontenoy, 75007 Paris, France, the UNESCO Office in Kabul, ICON Compound, Supreme Road, Off Jalalabad Road, PD 9, Kabul, Afghanistan, and Springer Nature Switzerland AG, Gewerbestrasse 1, 6330 Cham, Switzerland.

J. I. Jokilehto $(\bowtie)$

University of Nova Gorica, Nova Gorica, Slovenia 
perimeter of protection which would include the cliffs and the valley, and provide a map indicating the delimitation of this zone.' (SC/83/CONF.009/2) Unfortunately, the requested information was not received in time, and the nomination was deferred by the World Heritage Committee. In 1997, the Taliban declared that they would destroy the Bamiyan Buddhas with dynamite, which actually took place in March 2001. In October 2003, UNESCO General Conference adopted the Declaration concerning the Intentional Destruction of Cultural Heritage (UNESCO 2003a), declaring that a State that 'intentionally destroys or intentionally fails to take appropriate measures to prohibit, prevent, stop, and punish any intentional destruction of cultural heritage of great importance for humanity, whether or not it is inscribed on a list maintained by UNESCO or another international organization, bears the responsibility for such destruction, to the extent provided for by international law.' (article VI).

In 2003, the Afghan authorities, with the assistance of UNESCO, nominated the Cultural Landscape and Archaeological Remains of the Bamiyan Valley for urgent inscription on the World Heritage List and on the List of World Heritage in Danger. This proposal was accepted by the World Heritage Committee, and the property was inscribed on the basis of criteria: (i) (ii) (iii) (iv) and (vi), as 'a testimony of an important interchange of human values, over a span of time and within an important cultural area of the world, which contributed to the development in monumental artistic creativity and cultural exchange.' (UNESCO 2003b) The justification recognised the Gandharan School in Buddhist art, the intercultural influences with the Mediterranean art, the Buddhist cultural tradition of Central Asian region, as well as the importance of the Bamiyan Valley as an 'outstanding example of a cultural landscape which illustrates a significant period in Buddhism.' Furthermore, criterion (vi) stressed the importance of Bamiyan Valley for pilgrimage over several centuries and the shock of destruction in 2001.

Due to the international concern to have the property urgently inscribed, the 1983 recommendation was again not taken into account, and the nomination was limited to the cliffs with Buddhist caves and other archaeological sites, instead of including the entire valley. It can be noted that the Valley is already mentioned in ancient travel accounts by Chinese monks, from early fifth century to seventh and eighth centuries. The monk Xuanchang, who visited Bamiyan during Tang dynasty, tells that the Valley was then well inhabited by towns and dozens of monasteries. In late sixteenth century $\mathrm{CE}$, the gazetteer of the Akbar empire mentions the existence of around 12,000 grottoes forming part of an ensemble of Buddhist monasteries, chapels and sanctuaries along the foothills of the valley. Even though the nominated area was limited, the notion of cultural landscape is present in the title of the nomination, and it is also recognised in criterion (iv), which refers to the: 'cultural landscape that illustrates a significant period in Buddhism.' In fact, not only the cliffs are important in this valley; the entire historical-cultural territory must be taken into account when discussing the management of conservation and development. 


\section{Cultural Landscape and Cultural Territory}

In 1972, the World Heritage Convention became the first major international legal instrument to address the conservation of cultural as well as natural heritage as indicated in articles 1 and 2 of the convention. In the first years, cultural and natural heritage were generally considered separately. In the 1980s, however, there already started debate about the harmonious marriage of culture and nature. This became actual in 1987, when the UK nominated the Lake District National Park for inscription as a mixed cultural/natural site. At the time, it was deferred subject to clarification of the application of criteria. ${ }^{1}$ While ICOMOS agreed with the inscription, IUCN could not decide on the justification of natural criteria. As a result of further discussion, the notion of 'mixed cultural/natural sites' was considered an important issue to be clarified, particularly when the combination of cultural and natural attributes offered something exceptional and of universal interest, while the cultural or natural criteria separately could not justify World Heritage inscription. ${ }^{2}$

In 1992, the discussions resulted in the adoption by the World Heritage Committee of the notion of 'cultural landscape' as a new type of property qualifying for nomination. A working group was established for the revision of criteria, integrated into the Operational Guidelines in 1994. Consequently, as indicated in the Operational Guidelines: "Cultural landscapes represent the "combined works of nature and of man" designated in Article 1 of the Convention. They are illustrative of the evolution of human society and settlement over time, under the influence of the physical constraints and/or opportunities presented by their natural environment and of successive social, economic and cultural forces, both external and internal.' (p. 13) Cultural landscapes differ from 'mixed sites' and would normally be evaluated by ICOMOS jointly or in consultation with IUCN. Over the years, it has become increasingly clear that nature and culture must necessarily be managed together.

A key notion that has emerged from the debates over the past two decades is the recognition of the social, cultural, economic and environmental context, as also noted in the 2005 ICOMOS Xi' an Declaration on the Conservation of the Setting. In 2011, UNESCO adopted the Recommendation on Historic Urban Landscapes (UNESCO 2011b), which indicates that management can only be successful if it is based on the whole territory that protected areas are part of. In 2012, as a result of a United Nations Conference on Sustainable Development, 'Rio + 20' in Rio de Janeiro (UN 2012), the Heads of State and Government adopted a declaration on this issue: 'The Future We Want', where the strategic importance of sustainable management of natural resources and ecosystems was fully recognised for the conservation, regeneration and restoration and resilience in the face of new and emerging challenges. The notion of 'future we want' was also taken as the main

\footnotetext{
${ }^{1}$ The English Landscape District was finally inscribed in the World Heritage List under criteria (ii) (v)(vi), in 2017.

${ }^{2}$ UNESCO/WHC: 'Note on rural landscapes and the World Heritage Convention', 12 November 1987, SC-87/CONF.005/INF4.
} 
theme in The Kyoto Vision at the 40th anniversary of the World Heritage Convention. Buddhism has always given importance to nature and living with nature, and this is also stressed by Pope Francis in his Encyclical Letter Laudato Si' (2015). The Pope notes that Saint Francis of Assisi had already been 'an example par excellence of care for the vulnerable and of an integral ecology lived out joyfully and authentically. ${ }^{3}$ He continues, discussing the importance of guaranteeing integrity of healthy ecosystems, as a basis for healthy and balanced life on earth. From these examples also emerges the importance of again verifying what should be intended by the notions of integrity and authenticity, in verifying the conditions of cultural as well as natural heritage.

\section{Conservation and Management in Bamiyan}

The World Heritage property of the Cultural Landscape and Archaeological Remains of the Bamiyan Valley consists of eight protected components, including the Bamiyan Cliff with the two large niches that contained the gigantic Buddha figures. In reality, even though mentioned in the title, the cultural landscape of Bamiyan Valley is not included in the nominated areas, which only consist of the archaeological remains. The nomination does recognise the Valley as being 'of exceptional natural beauty and aesthetic importance' and moreover that 'the extraordinary natural setting composed of rugged mountains and cliffs, has experienced very few modern alterations in the past centuries'. In the justification of the OUV, criterion (i) is referred to the Gandharan Buddhist school - even though the major monuments are no more there. Therefore, the testimony of the Buddhist era consists of a seated Buddha figure and hundreds of caves with Buddhist paintings. The Valley also includes other ancient remains, such as the forts of Shahr-i Ghulghulah and Shahr-i Zuhak, not to speak of the archaeological potential of the entire region. The heritage value of the Bamiyan Valley should indeed be recognised in the combination of the characteristics that form the cultural landscape as a whole, rather than in an individual feature. However, like in the case of 'Bam and its Cultural Landscape', inscribed after the major earthquake in 2003, the serial World Heritage nomination of Bamiyan can be understood as a symbolic representation of the larger culturalnatural territory.

In his Theory of Restoration (1963), Cesare Brandi, director of the Italian State Institute for Restoration, focuses on 'works art'. Today these could be re-defined 'cultural expressions' as in the 2005 UNESCO Convention. ${ }^{4}$ For Brandi, 'Restoration consists of the methodological moment in which the work of art is recognized in its physical being and in its dual aesthetic and historical nature, in view of its

\footnotetext{
${ }^{3}$ The Holy See, 24 May 2015: Encyclical Letter Laudato Si' of the Holy Farther Francis on Care for Our Common Home, Libreria Editrice Vaticana (p. 4).

${ }^{4}$ UNESCO, Convention on the Protection and Promotion of the Diversity of Cultural Expressions, 2005
} 
transmission to the future. ${ }^{5}$ Consequently, according to the definition, the first and most fundamental part of 'restoration' is the recognition of the property concerned. It can be a work of art, and it can be a cultural expression. In the case of cultural landscape, recognition implies the knowledge of its qualities and characteristics, based on a systematic research and analysis of the historic territory, its ecosystems and natural features, as well as its human functions and relations over time, i.e. its functional, historical and visual integrity. Even though the World Heritage nomination, especially in reference to criteria (iii) and (iv), is focused on the Buddhist period, the planning and conservation of the cultural landscape necessarily imply identifying all the elements that together form the historical stratigraphy and morphology of the human and natural habitat as it exists in the present. The question, indeed, is not only to keep something from the past; it is also necessary to care for the needs of the community today and plan for the culturally and environmentally sustainable development of this historic territory into the future.

The methodology for the planning and management of historic urban and rural territories has gradually taken shape from the second half of the twentieth century. In October 1975, the Council of Europe adopted the European Charter of the Architectural Heritage, which introduced the notion of Integrated Conservation. The integrated conservation planning of historic areas was given to refer to the processes of culturally and environmentally sustainable development in historic areas, integrating conservation with the planning and management instruments, and it was specified that 'Integrated conservation depends on legal, administrative, financial and technical support, and the informed involvement of the heritage community as a whole.'

In practice, this normally means that there should be two integrated levels of action: territorial and architectural. On the territorial (urban and rural) level, the scope is to define the morphology and functional typology of the built and natural territory, i.e. how the traditional built areas have developed in response to the evolving requirements of the community. This includes a study of the condition and characteristics of cultivated areas, transport and communication systems as well as infrastructures. It also implies making a similar study of the natural and environmental features and ecosystems. On the level of the individual components of the territory, the question is to verify the state of conservation of the built complexes and open areas and verify the appropriate treatment to be integrated into the planning norms and guidelines. The management and implementation of the proposed guidelines would be the responsibility of a Management Commission, consisting of representatives of relevant public and private stakeholders. The Management Plan is required as a tool for the Management Commission and consists of the verification of the priorities and responsibilities for the implementation of the Integrated Conservation Master Plan.

\footnotetext{
${ }^{5}$ Cesare Brandi 2005, Theory of Restoration, ICR, Nardini Editore, Florence. Original Italian: 'Il restauro costituisce il momento metodologico del riconoscimento dell'opera d'arte, nella sua consistenza fisica e nella sua duplice polarità estetica e storica, in vista della sua trasmissione al futuro.' (Teoria del Restauro, Rome, 1963, p.34)
} 
In 2011, the World Heritage Committee adopted a statement concerning the Bamiyan Valley, encouraging feasibility studies, including 'an overall approach to conservation and presentation of the property, and an appropriate conservation philosophy based on the Outstanding Universal Value of the property, as well as technical and financial possibilities for the implementation of the project proposals' (UNESCO 2011a). Indeed, the requested Management Plan and a Cultural Master Plan have since been provided. Nevertheless, still in 2017, the Committee has expressed concern that the plans have not been implemented. At the same time, site security was not ensured, nor the long-term stability of the Giant Buddha niches and other archaeological remains, as recommended already in 2011. In the Tokyo conference in September 2017, there was discussion about the possible revision of the 2007 Cultural Master Plan (inventory), prepared by a German team, as well as the preparation of a Territorial Master Plan for the development of the Valley, which is currently being developed by an Italian team. These two plans should ideally be integrated into a balanced and efficient planning instrument, considering the entire territory as 'a coherent whole whose balance and specific nature depend on the fusion of the parts of which it is composed, and which include human activities as much as the buildings, the spatial organization and the surroundings.' ${ }^{6}$ The implementation of this planning instrument should be the responsibility of a Management Commission based on a periodically updated Management Plan as noted above.

\section{Discussion on the Buddha Niches}

The Ninth Expert Working Group Meeting (Paris, 3-4 March, UNESCO 2011) recommended that a total reconstruction of either of the Buddha sculptures cannot be considered at the present time. Furthermore, it was recommended that 'the larger western niche be consolidated and left empty as a testimony to the tragic act of destruction and that a feasibility study be undertaken to determine whether or not a partial reassembling of fragments of the Eastern Buddha could be as future option in the coming years'. The 2017 Tokyo meeting was a platform for the evaluation of the feasibility of alternative solutions. There were indeed several different ideas that were presented, extending from leaving both niches empty to suggesting different types of new creations to be built in the Eastern Buddha Niche.

At a minimum level, in 2011, Andrea Bruno had already proposed a long-term conservation and interpretation policy for the Western Buddha Niche. This would include an underground interpretation and observation space in front of the Buddha Niche. From here, one could see the Niche and have scale models illustrating the lost Buddha Figure. In a certain way, the UNESCO competition for a cultural

${ }^{6}$ UNESCO 1976, Recommendation concerning the Safeguarding and Contemporary Role of Historic Areas, article 3 
centre, currently in construction in the centre of the Valley, could be seen as a comparable solution. In the 2017 Tokyo meeting, the Japanese team proposed not to build anything in the Niche but to develop a museum complex on the opposite side of the Valley, which could also include a replica of the Eastern Buddha, but in a small scale. In principle, this option can be respected. It is noteworthy that the Japanese team, who are Buddhist, decided not to fill the Niche with a new figure.

There were basically three alternatives proposed for the Eastern Niche, involving new construction. One proposal consisted of using the original fragments of the destroyed Buddha Figure and identifying their original position on the basis of geological data. The fragments could then be placed on a steel structure imbedded in the back of the Niche. The second option was the construction of a new statue in mud brick, using local workforce. This statue would then have internal structure that would also fix it to the rock. The third option consisted of creating a full-scale 3D replica using Italian or Afghan marble. The replica would be mechanically carved as a thin layer (ca. $10 \mathrm{~cm}$ ) on the basis of original photographs. It would be built in small elements and fixed in a steel structure anchored to the rock. The statue could be unbuilt if required. It is necessary to recall that Afghanistan is seismic hazard region. Consequently, any tall and heavy construction would be vulnerable. Considering that the Niche is ca. $38 \mathrm{~m}$ tall (corresponding to a building of 12 stories), a heavy mud-brick statue would become much too heavy. The same could be said about the idea of placing original fragile rock fragments into the niche. In this regard the marble replica would probably be easier, considering that it would be less heavy and probably less vulnerable as was indicated in technical calculations during the Tokyo conference.

Restoration concerns the recognition of the heritage value of artistic and/or historic objects (monuments) that exist. The 1964 Venice Charter (UNESCO) states that: 'The process of restoration is a highly specialised operation. Its aim is to preserve and reveal the aesthetic and historic value of the monument and is based on respect for original material and authentic documents. It must stop at the point where conjecture begins, ...' (article 9) Strictly speaking, the construction of a new statue would not be 'restoration'. It could be a recreation or simply a new construction. Of course, the original Buddha figure was not constructed but carved from the fragile rock. Therefore, can we really speak of 'reconstruction' even if some remaining fragments are placed back to the niche?

Or can it be 'anastylosis'? Article 15 of the Venice Charter does mention the possibility of anastylosis, which is defined as: 'the re-assembling of existing but dismembered parts'. It is noted that the surface of the original Buddha Figures was in clay, and, in the 2001 explosion, all the surface was lost. The fragments that now have been collected are basically fragments of rock without form. Consequently, any attempt to restore the appearance of the Buddha is not possible only using those fragments. Even though these fragments actually have been part of the Buddha figure, they have not given the image. In fact, in his Teoria del restauro, Cesare Brandi distinguishes between image and matter, which are the two aspects of a work of art. The matter, which can consist of any type of material or structure, is the bearer of the manifested image, but it is the image that is the result of human creativity. While the physical 
means are necessary for the manifestation of the image, when the image is lost, we only have the matter without image. ${ }^{7}$ In the case of the destroyed Buddha Figures, the rock fragments do not even have historicity; they have never been touched by human hand (if not after destruction). Putting these formless fragments back to the Niche cannot be called anastylosis, because they are just material without form.

In human history, there have been several types of habitat. In early times, these included natural or rock-cut caves or dwellings built or constructed in a variety of materials, such as clay, stone or timber. Often, these forms of habitat could be combined, as is the case in Matera (Italy). In the World Heritage List, there are several Buddhist cave sites, including the Mogao caves in Western China. Here, as in many other places, the large Buddha caves were not necessarily open. Often, even large caves were closed with a wall. Consequently, one would enter a sacred place and appreciate the revelation of divine image. Traditionally sacredness means that a place is reserved. In the main Ise Shrine, only the priests can enter the sanctuary. In the case of Bamiyan Cliff, it is known that about $2 \mathrm{~m}$ of the rock surface has been lost over the centuries. Consequently, we cannot verify whether originally the caves were open or closed. It is indeed impossible to re-establish the original situation as there is not enough evidence. We understand that some members of the present-day community of Bamiyan have expressed the wish to re-create a Buddha image. We do appreciate such wish, and it will be necessary to do everything possible to valorise the significance of the Buddhist period within the overall historical, cultural and environmental context, as we have insisted above.

Today, recreating an image would mean introducing a new element in a site that has already been recognised for its OUV in reference to the archaeological remains of the Buddhist period and the cultural landscape. Parts of the remains consist of the numerous caves with Buddhist paintings and fragments of sculptures. In fact, the National Research Institute for Cultural Properties (NRICP) in Tokyo has undertaken and ensured some successful mural painting conservation. The two gigantic Niches that now remain open are very much part of this heritage. In fact, even though the original Buddha Figures have been destroyed, there are still fragmentary remains of the original form in the rock. Thus, the remaining rock surface carries authentic testimony to the sacred image that once was there. The Niche itself is an original cultural expression that needs to be respected and consolidated, as recognised in the World Heritage justification. These qualities could risk being partly hidden or undermined if some new element is placed there. In any case, even if a new statue, such as the proposed marble replica, were to be introduced into the Niche, it would necessarily need to be evaluated and assessed by the World Heritage Committee. It would be a new construction in an archaeological site, to be justified under the World Heritage criteria, and its impact assessed within the cultural landscape context of the Bamiyan Valley.

\footnotetext{
${ }^{7}$ See Chapter 2 ('La materia dell'opera d'arte') in: C. Brandi 1963, Teoria del Restauro, Rome, pp. 37-40: English edition: Theory of Restoration, Rome (2005).
} 


\section{A Word to Conclude}

As is noted in the justification of the World Heritage nomination, the cultural landscape and archaeological remains of the Bamiyan Valley represent the artistic and religious developments, which from the first to the thirteenth centuries characterised ancient Bactria, integrating various cultural influences into the Gandharan School of Buddhist art. It is known that the area has contained numerous Buddhist monastic ensembles and sanctuaries, within the fantastic natural setting of the mountain valleys. The territory also includes historic sites that document the Islamic period. Today, the community is conscious of their heritage but also requires planning and updating of services and infrastructures. As a priority, the current initiatives for the development of a comprehensive urban master plan based on knowledge of heritage resources and the potential of the territory must be integrated into a balanced territorial conservation master plan. The present management plan should necessarily be revised on the basis of this general master plan, and not be limited to archaeological areas alone. It is also essential to integrate these plans with the recognition and safeguarding of the natural environment and existing ecosystems that are part of the integrity and authenticity of the historicised territory.

There already exist a number of initiatives for safeguarding the cultural heritage, such as consolidating the cliffs and conserving the remains of Buddhist paintings and sculptures. The new cultural centre in the focal point of the Valley, currently under construction, will give an important opportunity to create a systematic capacity building programme at the community level. All these initiatives need to be integrated into a strategy of fund raising and financial programming. Regarding the gigantic Buddha niches, which are an integral part of the historical significance of the Bamiyan Valley, priority should be given to the urgent completion of consolidation and the continuation of safeguarding of the remains. It is not advisable to propose any reconstruction or anastylosis in the ancient niches. The present remains are the most efficient memorial to the 2001 destruction, and they are the most authentic and prestigious monument for the history of the Bamiyan Valley and its community. It is necessary also to care for the remains of the traditional building stock, which still exists in various parts of the territory. These buildings should be surveyed and eventually rehabilitated in an appropriate type of social or cultural use.

\section{References}

Brandi, C. (2005). Theory of restoration, ICR, Nardini Editore, Florence (Teoria del Restauro, Rome, 1963).

Council of Europe. (1975). The European charter of the architectural heritage.

ICOMOS. (2005). Xi'an declaration on the conservation of the setting of heritage structures, sites and areas.

Pope Francis. (2015). Encyclical letter Laudato Si' of the Holy Farther Francis on care for our common home. Vaticana: Libreria Editrice. 
UN (2012). The future we want, outcome document of the United Nations conference on sustainable development, "Rio+20" in Rio de Janeiro, 20-22 June 2012.

UNESCO. (1964). International charter for the conservation and restoration of monuments and sites (The Venice Charter, adopted by ICOMOS in 1965).

UNESCO. (1976). Recommendation concerning the safeguarding and contemporary role of historic areas.

UNESCO. (1983). World Heritage: SC/83/CONF.009/2.

UNESCO. (2003a). Declaration concerning the intentional destruction of cultural heritage.

UNESCO. (2003b) World heritage property: 'Cultural landscape and archaeological remains of the Bamiyan Valley'. http://whc.unesco.org/en/list/208

UNESCO. (2005). Convention on the protection and promotion of the diversity of cultural expressions.

UNESCO. (2011a). World Heritage: 35 COM 7A.25.

UNESCO. (2011b). Recommendation on historic urban landscapes.

UNESCO. (2012). The Kyoto Vision at the 40th anniversary of the World Heritage Convention.

UNESCO, World Heritage. (2011). Recommendations of the 9th Expert Working Group Meeting for the Preservation of the Cultural Landscape and Archaeological remains of the Bamiyan Valley World Heritage Property, Afghanistan, UNESCO Headquarters (3 and 4 March 2011).

The opinions expressed in this chapter are those of the author(s) and do not necessarily reflect the views of the UNESCO, its Board of Directors, or the countries they represent.

Open Access This chapter is licensed under the terms of the Creative Commons AttributionShareAlike 3.0 IGO License (https://creativecommons.org/licenses/by-sa/3.0/igo/), which permits use, sharing, adaptation, distribution, and reproduction in any medium or format, as long as you give appropriate credit to UNESCO, provide a link to the Creative Commons licence and indicate if changes were made. If you remix, transform, or build upon this chapter or a part thereof, you must distribute your contributions under the same licence as the original. This publication is also available at the UNESCO Open Access Repository: https://unesdoc.unesco.org/

The designations employed and the presentation of material throughout this publication do not imply the expression of any opinion whatsoever on the part of UNESCO concerning the legal status of any country, territory, city or area or of its authorities, or the delimitation of its frontiers or boundaries.

The authors are responsible for the choice and the presentation of the facts contained in this chapter and for the opinions expressed therein, which are not necessarily those of UNESCO and do not commit the Organization.

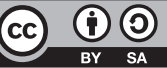

